\title{
Has the Opportunity Gone Up in Smoke?
}

Just after the release of the 2000 clinical practice guidelines "Treating Tobacco Use and Dependence," I remember reading a stirring editorial written by Sam Giordano. The title was "What's That Sound?" In the editorial, Giordano urged respiratory therapists (RTs) to become conversant with the guidelines and to "seize this incredible opportunity to add value" to the services provided by RTs. I recently re-read this editorial and was struck by how familiar many of the themes in this now 13-year-old editorial rang. Some examples: As a country, we are unable to control healthcare costs. Healthcare reform is underway. Reducing health risks, such as tobacco use-the primary avoidable cause of morbidity and mortality in the United States - could eventually reduce the demand on healthcare services, resulting in more judicious use of healthcare resources. ${ }^{1}$ How much, I wonder, has really changed in the past 13 years?

Giordano also warned the reader that smoking cessation interventions will go forward "with or without" RTs as the healthcare professional who assumes the role of the smoking cessation specialist. He built the case for why this role is a good fit for our profession, and suggested that the sound we hear is "opportunity knocking." It is time, he said, for RTs to have a leadership role in targeting the number one health risk in our country, because it is the "smart thing to do" and it's also the "right thing to do"! 1

Since Giordano wrote that editorial there has been a plethora of evidence available in the literature about the efficacy and cost-effectiveness of tobacco cessation interventions. Yet there has been very little written about the efficacy of the RT's role in providing those tobacco cessation interventions. And, unfortunately, most of what has been published does not demonstrate strong empirical support for the role of the RT in this area.

Motivated by re-reading this editorial, I searched the literature over the past 15 years for studies in which the role of the RT as a smoking cessation specialist was characterized. I found a study that showed favorable attitudes among almost $400 \mathrm{RT}$ students and practitioners about having a role in tobacco treatment and other prevention counseling ${ }^{2}$; another study demonstrated that the RT was actually ineffective as a tobacco counselor, compared to usual care ${ }^{3}$; a pilot study found that RTs were effective facilitators in a smoking cessation program for parents of children in a children's hospital ${ }^{4}$; and an excellent review and 2 compelling editorials, all of which implored RTs to assume the role of a smoking cessation counselor. ${ }^{5-7}$ To my knowledge, this is the extent of what has been published since Mr Giordano's editorial in 2000 about the RT's role in tobacco control and prevention! Thus, I have concluded that the number of RTs who provide smoking cessation counseling in the United States is relatively small and those who do assume this role, however passionately they approach it, are not disseminating their work.

See the Original Study on Page 1299

In this issue of Respiratory CARE, Tremblay et al describe a collaborative effort between 2 Canadian agencies to provide educational interventions and to systematically assess the tobacco practices of healthcare practitioners in Québec, Canada. ${ }^{8}$ In this study they compare the differences in self-reported characteristics such as beliefs, selfefficacy, knowledge of community resources, barriers, and number of patients counseled by RTs at 2 different points in time (2005 and 2010). The study also seeks to determine if differences in these scores are the result of training received "during studies" (as part of the RT's formal respiratory care education) or "after studies" (as part of the RT's continuing education). Although there are some limitations, this study is important because it has begun to fill an important gap that has existed in the literature for years - at least since 2000 - about the role of the RT as a smoking cessation counselor.

Just like Giordano in 1998, I believe that there are many reasons for RTs here in the United States to embrace the role of smoking cessation specialist at this time in our history. Under our current system of healthcare reform, there are opportunities in both the acute care and chronic care settings. Of central importance is the baby-boomer generation, who will account for over $\$ 1$ trillion in annual Medicare spending by $2022 .{ }^{9}$ Many of these older patients have chronic health disorders, including COPD, and many of them are tobacco users.

Medicare has implemented or will implement a number of policies that will affect how hospitals are reimbursed. These policies include adjustments in annual payments to hospitals based on performance outcomes (value-based purchasing), re-hospitalization within 30 days of discharge (readmission reduction program), and the degree to which 
patients received medically necessary treatment while in the hospital (post-payment recovery audits). ${ }^{9}$

Although COPD is not covered by the value-based purchasing or the readmission reduction program now, it is likely to be included in time. ${ }^{10}$ In any case, the thing that patients who are admitted with diagnoses that are currently included (acute myocardial infarction, congestive heart failure, pneumonia) are likely to have in common is cigarette smoking! Listen! What's that sound?

Change is occurring in Medicare policies in the primary care setting also. The Affordable Care Act mandates chronic disease management as part of an "essential benefits" package offered by the new insurance exchanges..$^{10}$ RTs have the expertise to educate patients about their pulmonary disease and to teach them about symptoms and triggers, how to recognize an exacerbation, and how to stop tobacco use. Smoking cessation will be one of the chronic disease management services included in the proposed Medicare Respiratory Therapist Access Act. ${ }^{10}$ Passage of this act will allow RTs to provide these services in the physician's office setting. In this way, RTs in the pulmonary physician's office will be supporting the work of RTs in the hospital to prevent hospital readmissions for the Medicare recipient with a diagnosis of COPD. This will have a positive impact on transitions, with an emphasis on patient education and self-management. It is important to begin work on this as soon as possible, since COPD is likely to be added to the hospital readmissions reduction conditions list in $2015 .{ }^{10}$ Listen! What's that sound?

The data shared by Tremblay et al show that smoking cessation education, received either during the professional education or afterward during a continuing education program, improves the likelihood that an RT will engage in smoking cessation counseling. Not surprising! How can United States educational programs ensure that graduates are prepared to provide tobacco education and prevention services? Few would disagree that our current associate degree programs in respiratory care are hard pressed to include more than a cursory discussion of smoking cessation in their curricula. It is simply not practical, given the volume of competencies faculty are required to ensure today's graduates meet, and the short time educators in these programs have to accomplish their goals.

The proposed Medicare Respiratory Therapist Access Act has revised the RT qualifications to state that the RT

The author has disclosed no conflicts of interest.

Correspondence: Erna L Boone DrPH RRT FAARC, Department of Respiratory and Surgical Technologies, College of Health Professions, University of Arkansas for Medical Sciences, $4301 \mathrm{~W}$ Markham, \#737, Little Rock AR 72205. E-mail: booneernal@uams.edu.

DOI: $10.4187 /$ respcare. 02617 must hold the Registered Respiratory Therapist (RRT) credential and at a minimum have a bachelor's degree or other advanced degree in a health science field. ${ }^{10}$ Given that the majority of RT graduates are from associate degree programs in the United States, ${ }^{11}$ educators, accreditors, credentialing agents and the leaders in the American Association for Respiratory Care will need to continue to reform the education, accreditation, and credentialing system to meet the recommendations of "2015 and Beyond,"12 including ensuring that adequate smoking cessation education is provided to every RT graduate, and that it is made available to every RT practitioner. Listen! What's that sound?

I applaud the 6 Canadian health professional groups that collaborated to develop interventions and aids to augment cessation practices, as well as Tremblay et al, whose assessment of those practices will guide future training and educational interventions for practicing RTs in Québec. I am hopeful that we will see more empirical descriptions of the role of the RT in smoking cessation here in the United States in the future. There are certainly some great opportunities for RTs to have key roles in eliminating the leading preventable cause of death and disability in the United States. Seems like the smart thing to do. Seems like the right thing to do. But, like Sam Giordano said in 1998, "smoking cessation interventions will move forward with or without us." I think it is very possible that we are hearing the sound of opportunity knocking once again. I hope this opportunity doesn't go up in smoke!

Erna L Boone DrPH RRT FAARC Department of Respiratory and Surgical Technologies College of Health Professions University of Arkansas for Medical Sciences Little Rock, Arkansas

\section{REFERENCES}

1. Giordono SP. What's that sound? Respir Care 2000;45(10):11671168.

2. Sockrider MM, Maguire GP, Haponik E, Davis A, Boehlecke B, Attitudes of respiratory care practitioners and students regarding pulmonary prevention. Chest 1998;114(4):1193-1198.

3. Stevens VJ, Glasgow RE, Hollis JF, Mount K. Implementation and effectiveness of a brief smoking-cessation intervention for hospital patients. Med Care 2000;38(5):451-459.

4. Cohn RC, Dodson D, French A, Ervin B, Ciarlariello S, Wilson TN. A pilot smoking cessation program run by pediatric respiratory care practitioners for parents. Clin Pediatr (Phila) 2000;39(2):121-124.

5. Marlow SP, Stoller JK. Smoking cessation. Respir Care 2003;48(12): 1238-1254.

6. Waugh JB, Lorish CD. New guideline on treating tobacco use and dependence: 2008 update is an opportunity to advance. Respir Care 2008;53(9):1166-1168. 


\section{Has the Opportunity Gone Up IN SMOKe?}

7. Goodfellow LT, Waugh JB. Tobacco treatment and prevention: what works and why? Respir Care 2009;54(8):1082-1090.

8. Tremblay M, O'Loughlin J, Comtois D. Respiratory therapists' smoking cessation counseling practices: a comparison between 2005 and 2010. Respir Care 2013(8):1299-1306.

9. Dunne PJ. Health care reform \& respiratory care: a defining moment. AARC Times 2013;37(5):44-48.

10. American Association for Respiratory Care. Medicare Respiratory Therapist Access Act: frequently asked questions. Revised Febru- ary 2013. http://www.aarc.org/advocacy/pact/pact_aqs_013.pdf. Accessed May 24, 2013.

11. Commission on Accreditation for Respiratory Care. 2012 report on accreditation in respiratory care. $c 17$ http://www.coarc.com/uploaded/ files $/ 2012 \% 20$ CoARC\%20Report\%20on\%20Accreditation\%203.23. 13.pdf. Accessed May 24, 2013.

12. Barnes TA, Kacmarek RM, Kageler WV, Morris MJ, Durbin CG Jr. Transitioning the respiratory therapy workforce for 2015 and beyond. Respir Care 2011;56(5):681-690. 